\title{
A general route of using lignite depolymerized derivatives for catalyst construction: insights into the effects of the derivative structures and solvents
}

\author{
Jianxiu Hao *, Limin Han, Keli Yang, Na Li, Runxia He, Keduan Zhi, Quansheng Liu * \\ Chemical Engineering, Inner Mongolia University of Technology; Inner Mongolia Key Laboratory of High-Value \\ Functional Utilization of Low Rank Carbon Resources, Hohhot 010051, Inner Mongolia, China;
}

\section{The contents list}

S1 Studies of the preparation conditions of $\mathrm{Cu}-\mathrm{DM}$ catalyst

$\mathrm{S} 2$ Characterization results of $\mathrm{Cu}-\mathrm{DM}$ catalyst

S3 Activity comparison of $\mathrm{Cu}-\mathrm{DM}$ with other benzyl alcohol oxidation catalysts

S4 Heterogeneity and reusability of $\mathrm{Cu}-\mathrm{DM}$ catalysts

\footnotetext{
${ }^{1}$ This author's current address (Wuhai Vocational \& Technical College, Wuhai 010070, Inner Mongolia, China.) differs from the research affiliation.
} 


\section{S1 Studies of the preparation conditions of $\mathrm{Cu}-\mathrm{DM}$ catalyst}

In the preparation of $\mathrm{Cu}-\mathrm{DM}, \mathrm{Cu}\left(\mathrm{CH}_{3} \mathrm{COO}\right)_{2} \cdot \mathrm{H}_{2} \mathrm{O}$ and DM catalysts with mass ratios of $1: 4,1: 2,1: 1,2: 1$ and $4: 1$ were prepared in order to determine the appropriate ratio of copper precursor to DM. The phenomenon of centrifugation for each proportion of samples was shown in Figure S1. It could be seen from the figure that DM presented a brown solution in water without copper. When the ratios of the two were $2: 1$ and $4: 1$, the centrifugal supernatant was dominated by the green color of copper ions, and the brown color of DM disappeared. It was believed that the coordination combination of carboxylic acids and copper precursor in DM was sufficient at this time, forming a large amount of precipitation, and $\mathrm{Cu}^{2+}$ was in an excessive state. In order to further screen out the most suitable ratio, the catalytic oxidation of benzyl alcohol to benzaldehyde was used as a model reaction to investigate the activity of the two catalysts, as shown in Table S1. The results showed that the conversion and selectivity of $2: 1$ were higher than those of the ratio of $4: 1$, and thus the ratio of copper to DM was ultimately chosen as 2:1. 


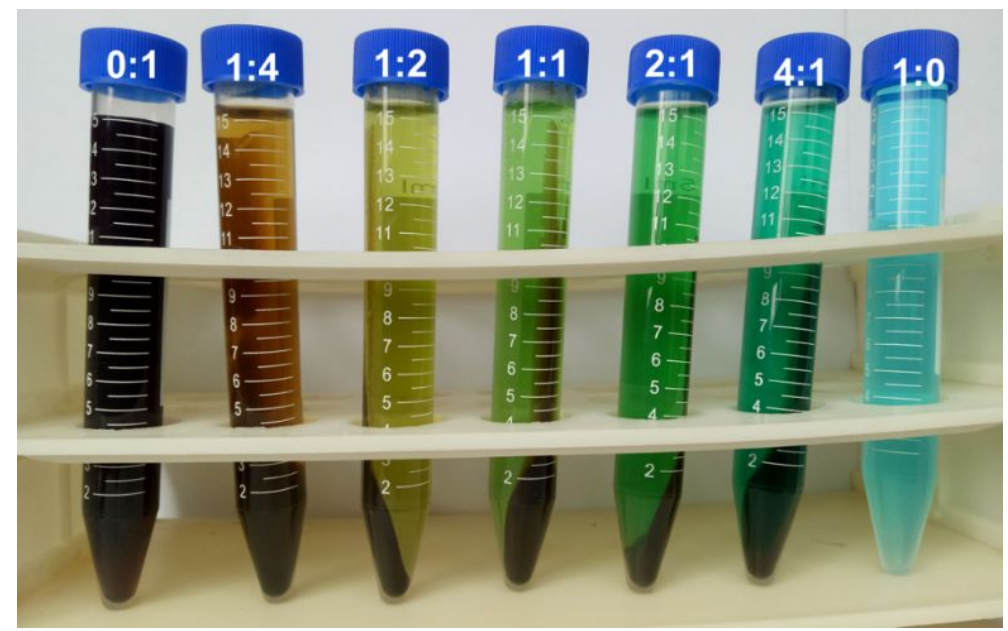

Figure S1 Optical images of $\mathrm{Cu}$-DM catalysts prepared at different mass ratios of

$$
\mathrm{Cu}\left(\mathrm{CH}_{3} \mathrm{COO}\right)_{2} \cdot 8 \mathrm{H}_{2} \mathrm{O} \text { to } \mathrm{DM}
$$

Preparation condition: $30^{\circ} \mathrm{C}, 3 \mathrm{~h}$.

Table S1. Comparison of the catalytic activities of $\mathrm{Cu}-\mathrm{DM}$ catalysts prepared under different conditions.

\begin{tabular}{llll}
\hline Sample & Conv.\% & Yield\% & Sel.\% \\
\hline Cu-DM (2:1) & 46.5 & 43 & 92.6 \\
Cu-DM (4:1) & 35.9 & 34.3 & 95.4 \\
\hline
\end{tabular}

Reaction conditions: $80^{\circ} \mathrm{C}, 1.5 \mathrm{~h}$; alcohol $(1 \mathrm{mmol})$, Catalyst $(40 \mathrm{mg}), \mathrm{Na}_{2} \mathrm{CO}_{3}(1 \mathrm{mmol})$, TEMPO (0.5 mmol), DMF (5 mL), $\mathrm{O}_{2}(0.1 \mathrm{MPa})$.

\section{S2. Characterization results of $\mathrm{Cu}-\mathrm{DM}$ catalyst}



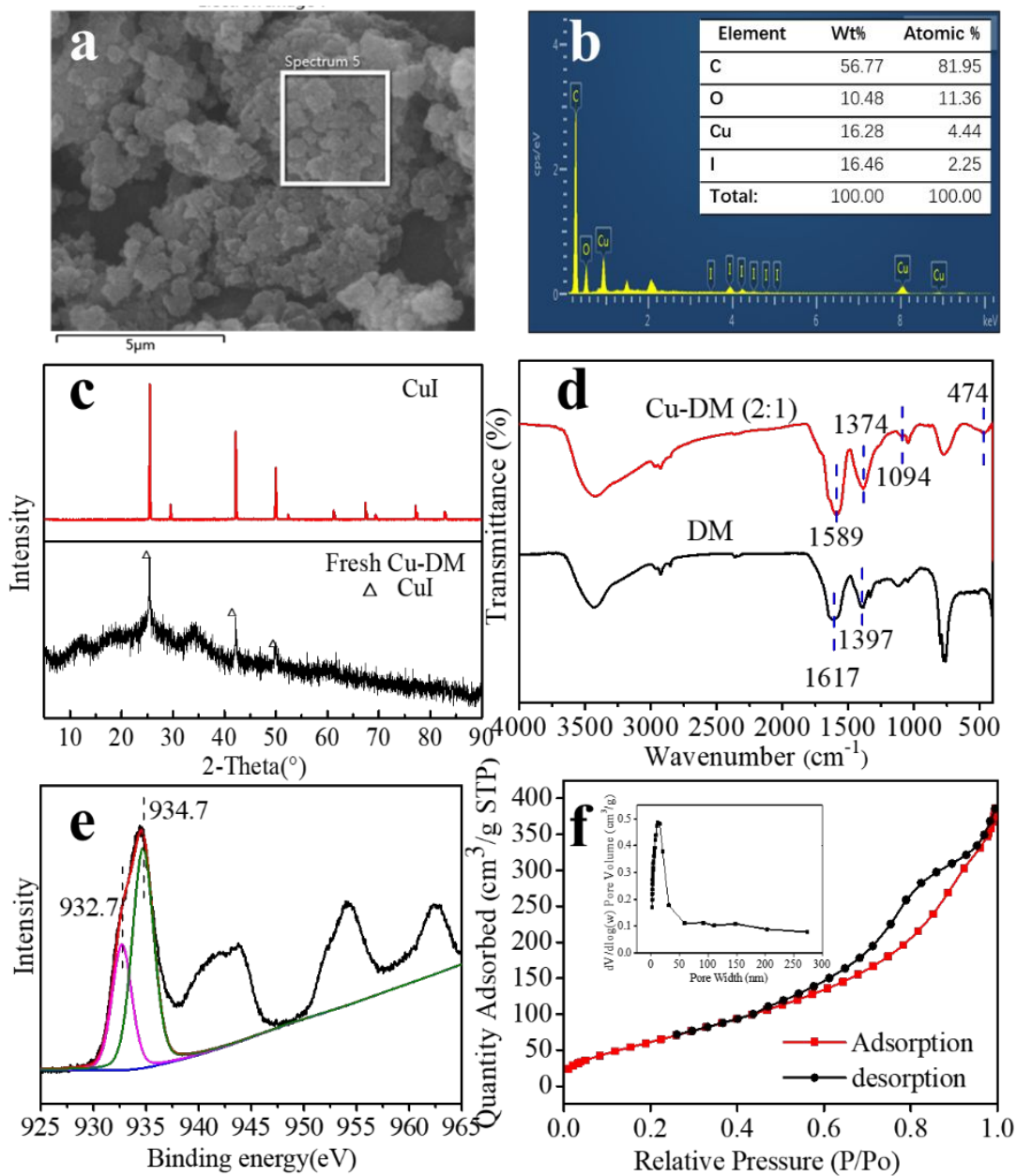

Figure S2. Characterization of the as-prepared Cu-DM catalyst by SEM (a), EDS (b), XRD spectra (c), FTIR pattern (d), XPS spectrum (e) and $\mathrm{N}_{2}$ adsorption-desorption isotherms (f, inserted figure, pore size distributions).

SEM analysis was used to study the morphology of $\mathrm{Cu}-\mathrm{DM}$, as shown in Figure $\mathrm{S} 2 \mathrm{a}, \mathrm{Cu}-\mathrm{DM}$ presented as small aggregates composed of irregular particles. EDS characterization of $\mathrm{Cu}-\mathrm{DM}$ showed that there were signal peaks of $\mathrm{Cu}$ and I elements. The crystal structure of $\mathrm{Cu}-\mathrm{DM}$ was characterized by powder $\mathrm{XRD}$, as shown in Figure S2c. The results showed that $\mathrm{Cu}-\mathrm{DM}$ had an amorphous structure, but it had the diffraction peak of $\mathrm{CuI}$ crystal, indicating that $\mathrm{CuI}$ and $\mathrm{Cu}-\mathrm{DM}$ co-existed in the amorphous $\mathrm{Cu}-\mathrm{DM}$ structure ${ }^{1}$. Compared with the FTIR spectrum of DM, the $\mathrm{Cu}-\mathrm{DM}$ 
sample presented $\mathrm{C}=\mathrm{O}$ stretching vibration peak at $1589 \mathrm{~cm}^{-1}$ and $\mathrm{C}-\mathrm{O}$ symmetric stretching vibration peak at $1374 \mathrm{~cm}^{-1} 2$. Meanwhile, the $\mathrm{Cu}-\mathrm{O}$ specific stretching vibration peak at $474 \mathrm{~cm}^{-1}$ and $1094 \mathrm{~cm}^{-1}$, which proved the successful combination of some copper and oxygen-containing functional groups in DM (Figure S2d).

In order to reveal the chemical state of copper in $\mathrm{Cu}-\mathrm{DM}$, the local environment of $\mathrm{Cu}$ species in catalyst was detected by XPS (Figure S2e). In $\mathrm{Cu} 2 \mathrm{p}$ core level photoelectron spectra, the two peaks between 950.0 and $965.0 \mathrm{eV}$ are $\mathrm{Cu} 2 \mathrm{P} 1 / 2$ electron energy combining center peak and satellite peak. The main $\mathrm{Cu} 2 \mathrm{p} 3 / 2$ signal was composed of two contributions at 932.7 and $934.7 \mathrm{eV}$, where the former was assigned to $\mathrm{Cu}^{+/ 0}$ and the latter to $\mathrm{Cu}^{2+3-5} \cdot \mathrm{Cu}^{+}$and $\mathrm{Cu}^{0}$ are hard to discriminate because they only have a difference of $\sim 0.3 \mathrm{eV}$ difference in binding energy, whereas $\mathrm{Cu}^{+/ 0}$ and $\mathrm{Cu}^{2+}$ have a difference of more than $2 \mathrm{eV}$. The appearance of satellite peaks between 937.0 and $947.0 \mathrm{eV}$ also confirmed the existence of divalent copper ${ }^{6}$. Therefore, the prepared $\mathrm{Cu}-\mathrm{DM}$ catalyst contained both $\mathrm{Cu}^{+/ 0}$ and $\mathrm{Cu}^{2+}$. Characterized by SEM-EDS and $\mathrm{XRD}, \mathrm{Cu}^{+/ 0}$ and $\mathrm{Cu}^{2+}$ correspond to $\mathrm{CuI}$ and $\mathrm{Cu}-\mathrm{DM}$ respectively, and they existed together.

The nitrogen adsorption-desorption isotherms showed that the $\mathrm{Cu}-\mathrm{DM}$ catalyst was type IV isotherm, with hysteresis loops characteristic of mesoporous materials 7,8 centered around $12 \mathrm{~nm}$ (Figure S2f) and the specific surface area $242.8 \mathrm{~m}^{2} \mathrm{~g}^{-1}$.

\section{S3. Activity comparison of $\mathrm{Cu}-\mathrm{DM}$ with other benzyl alcohol oxidation catalysts}

The performance of the prepared $\mathrm{Cu}-\mathrm{DM}$ catalyst was compared with other commonly reported catalysts for aerobic oxidation of benzyl alcohol (Table S2). It 
was found that the $\mathrm{Cu}-\mathrm{DM}$ catalyst prepared in this work showed similar or even better performance than other catalysts (Entries 2-11) under mild conditions. Only 1.5 h was needed to reach a yield of higher than $90 \%$ at $120{ }^{\circ} \mathrm{C}$ and the amount of catalyst was lower than other catalysts. Compared with the catalysts reported in other literatures, the $\mathrm{Cu}-\mathrm{DM}$ catalyst constructed in this work had some obvious advantages. On one hand, the raw materials for the preparation of the catalyst are the DM obtained by RICO of lignite, which are more common, low-cost, and naturally available. On the other hand, the preparation process of the catalysts is simpler than other catalysts (e.g. $\mathrm{Cu}_{3}(\mathrm{BTC})_{2}$ MOFs) because DM can be used directly with no need of complex purification in water. These advantages combining with the excellent activity and selectivity of the catalyst, made the catalyst competitive among the analogues reported in the literatures.

Table S2 Activity comparison of Cu-DM with other benzyl alcohol oxidation catalysts ${ }^{a}$

\begin{tabular}{|c|c|c|c|c|c|c|c|}
\hline Entry & Catalyst & $\mathrm{T}\left({ }^{\circ} \mathrm{C}\right)$ & t (h) & $\begin{array}{l}\text { Yield } \\
(\%)\end{array}$ & $\begin{array}{l}\text { Conv. } \\
(\%)\end{array}$ & $\begin{array}{l}\text { Sel. } \\
(\%)\end{array}$ & Ref. \\
\hline 1 & $\mathrm{Cu}-\mathrm{DM}$ & 120 & 1.5 & 90.5 & 92.7 & 97.6 & This work \\
\hline $2^{b}$ & $\mathrm{Cu}(\mathrm{OAc})_{2} \cdot \mathrm{H}_{2} \mathrm{O}$ & 80 & 1.5 & 94.3 & 96.0 & 98.2 & 9 \\
\hline $3^{c}$ & $\mathrm{Cu}-\mathrm{Dpps}$ & 100 & 2.0 & 90.0 & 90.6 & 99.4 & 9 \\
\hline $4^{d}$ & $\mathrm{Cu}_{3}(\mathrm{BTC})_{2}$ & 75 & 22.0 & 91 & - & - & 10 \\
\hline $5^{e}$ & $\mathrm{Cu}_{3}(\mathrm{BTC})_{2}$ & 75 & 3.0 & 96 & 97 & $>99$ & 11 \\
\hline $6^{f}$ & $\mathrm{Cu}_{3}(\mathrm{BTC})_{2}$ & 75 & 3.0 & 97 & $>99$ & $>98$ & 8 \\
\hline $7 g$ & $\begin{array}{l}\text { SPS-Cu } \\
\text { (II)@ } \mathrm{Cu}_{3}(\mathrm{BTC})_{2}\end{array}$ & 75 & 8.0 & $>99$ & - & - & 12 \\
\hline $8^{h}$ & $\mathrm{Cu}(\mathrm{I}) / \mathrm{NMI}$ & 25 & 24.0 & 44 & - & - & 13 \\
\hline $9^{i}$ & (bpy)Cu(I) & 27 & 3.0 & 95 & - & - & 14 \\
\hline
\end{tabular}




\begin{tabular}{llllcccc}
$10^{j}$ & $\mathrm{Fe}(\mathrm{OTs})_{3} \cdot 6 \mathrm{H}_{2} \mathrm{O}$ & 60 & 16 & 85.6 & 89.3 & 96 & 15 \\
$11^{k}$ & $\mathrm{Co} / \mathrm{C}-\mathrm{N} 700$ & 110 & 48 & 98 & 98 & 100 & 16 \\
\hline
\end{tabular}

${ }^{a}$ Typical reaction conditions were as follows except for otherwise stated in the table: benzyl alcohol $1 \mathrm{mmol}$, catalyst $160 \mathrm{mg}$, TEMPO $0.5 \mathrm{mmol}, \mathrm{Na}_{2} \mathrm{CO}_{3} 1 \mathrm{mmol}$, DMF $5 \mathrm{~mL}, \mathrm{O}_{2} 0.1 \mathrm{Mpa}$.

${ }^{b}$ The homogeneous property, difficult to recycle

${ }^{c}$ Dpps: depolymerized products of lignite by alkali-oxygen oxidation; benzyl alcohol $1 \mathrm{mmol}$, catalyst $200 \mathrm{mg}$, TEMPO $0.5 \mathrm{mmol}$, Na2CO3 $1 \mathrm{mmol}$, DMF $5 \mathrm{~mL}$, O2 0.1Mpa.

${ }^{d}$ BTC: Trimesic acid. Benzyl alcohol $0.925 \mathrm{mmol}$, catalyst $150 \mathrm{mg}$, TEMPO $288 \mathrm{mg}, \mathrm{Na}_{2} \mathrm{CO}_{3} 85$ $\mathrm{mg}$, acetonitrile $5 \mathrm{~mL}$, oxygen atmosphere.

${ }^{e}$ The $\mathrm{Cu}_{3}(\mathrm{BTC})_{2}$ MOFs synthesized in $\mathrm{CO}_{2}$-expanded DMF, benzyl alcohol $0.185 \mathrm{mmol}$, catalyst $30 \mathrm{mg}$, TEMPO 0.5 equiv, $\mathrm{Na}_{2} \mathrm{CO}_{3} 1$ equiv, DMF $1 \mathrm{~mL}, \mathrm{O}_{2} 0.1 \mathrm{MPa}$.

$f$ The $\mathrm{Cu}_{3}(\mathrm{BTC})_{2}$ MOFs synthesized in P104/PEG solution (P104= $=\mathrm{EO}_{27} \mathrm{PO}_{61} \mathrm{EO}_{27}$, PEG=Poly(ethylene glycol)), benzyl alcohol $0.185 \mathrm{mmol}$, catalyst $30 \mathrm{mg}$, TEMPO $5 \mathrm{mg}$, acetonitrile $1 \mathrm{~mL}, \mathrm{O}_{2} 0.1 \mathrm{MPa}$.

${ }^{g}$ SPS-Cu(II)@Cu $(\mathrm{BTC})_{2}$ catalyst consisted of a functional sulfonated-polystyrene (SPS) core, a porous $\mathrm{Cu}_{3}(\mathrm{BTC})_{2}$ shell and an active $\mathrm{Cu}(\mathrm{II})$ interface between the core and shell. Benzyl alcohol $1 \mathrm{mmol}$, catalyst $2 \mathrm{~mol} \%$, TEMPO $0.09 \mathrm{mmol}$, acetonitrile $5 \mathrm{~mL}, \mathrm{O}_{2} 0.1 \mathrm{MPa}$ and 1 mmol nitrobenzene.

${ }^{h}$ Homogeneous $\mathrm{Cu}(\mathrm{I}) / \mathrm{NMI} / \mathrm{TEMPO}$. Benzyl alcohol $5 \mathrm{mmol}$, NMI $0.5 \mathrm{mmol}$, CuI $0.25 \mathrm{mmol}$, TEMPO $0.25 \mathrm{mmol}, \mathrm{CH}_{3} \mathrm{CN} 5 \mathrm{~mL}$, air.

${ }^{I}$ Pyridine(bpy) as a ligand, $\mathrm{Cu}(\mathrm{OTf}) 5 \mathrm{~mol} \%$, bpy $5 \mathrm{~mol} \%$, TEMPO $5 \mathrm{~mol} \%$, and NMI $10 \mathrm{~mol} \%$ in $\mathrm{MeCN} 0.2 \mathrm{M}$.

${ }^{j}$ P-toluenesulfonic acid (OTs) was used to construct the catalyst, catalyst $0.1 \mathrm{mmol}, \mathrm{BnOH} 10$ 
mmol, Chloroform $10 \mathrm{~g}, \mathrm{n}\left(\mathrm{H}_{2} \mathrm{O}_{2}\right): \mathrm{n}(\mathrm{BnOH})=6: 1$.

${ }^{k}\left(\mathrm{Co}_{9}(\mathrm{btc})_{6}(\mathrm{tpt})_{2}\left(\mathrm{H}_{2} \mathrm{O}\right)_{15}\right) \cdot$ solvent $(\mathrm{tpt}=2,4,6$-tris(4-pyridyl)-1,3,5-triazine) was selected as the MOF precursor to construct Co/C-N700 catalyst. Benzyl alcohol $0.5 \mathrm{mmol}, \mathrm{Co} / \mathrm{C}-\mathrm{N} 700$ (10 mol\% $\mathrm{Co}), \mathrm{H}_{2} \mathrm{O} 0.5 \mathrm{~mL}$, air.

\section{S4. Heterogeneity and reusability of Metal-DM catalysts}

The cyclic usability and heterogeneity of the prepared $\mathrm{Cu}-\mathrm{DM}$ catalyst were investigated, and the experimental results were shown in Figure S3. The reaction conditions were controlled so that the conversion rate of benzyl alcohol and the yield of benzyl formaldehyde reached about $50 \%$, and the cyclic stability of the catalyst was investigated under these conditions. After the first reaction, the catalyst solids were separated by centrifugation, washed three times with DMF solvent, and transferred to the new reaction system for the second use. The following reaction conditions and treatment methods were the same as the first time. It can be seen from the Figure S3a that the reaction results were basically the same in the subsequent reactions, indicating that the catalytic activity remained basically stable after 5 cycles of cyclic use of the catalyst, and the catalyst had a good cycling usability.

The heterogeneity of catalyst was investigated in a similar way to that of Zr-DM in the main text. When the reaction was stopped after $30 \mathrm{~min}$, the catalyst in the reaction system was removed by centrifugal separation, and the centrifugal supernatant continued to react under the original conditions, as shown in Figure S3b. As can be seen from the figure, after the catalyst was removed, the reaction time continued to be prolonged, and the yield of benzaldehyde was basically the same as that at $30 \mathrm{~min}$, 
which was significantly different from the reaction results with the catalyst, indicating that the reaction stopped immediately after the catalyst was separated by centrifugation. Therefore, the $\mathrm{Cu}-\mathrm{DM}$ catalyst prepared were considered to be the heterogeneous catalyst.
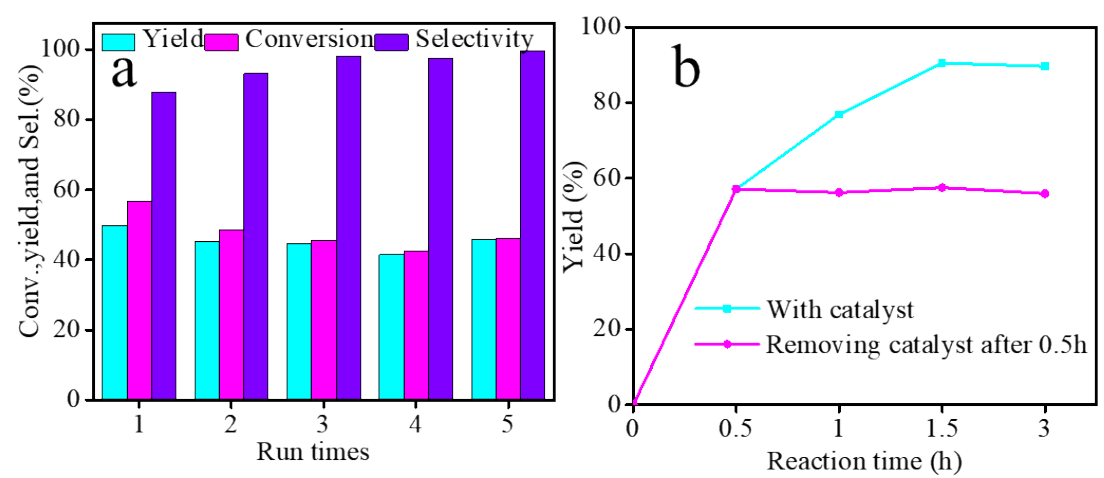

Figure S3 Reusability(a) and heterogeneity(b) of the Cu-DM catalyst.

Reaction conditions: benzyl alcohol $1 \mathrm{mmol}$, catalyst $160 \mathrm{mg}$, TEMPO $0.5 \mathrm{mmol}, \mathrm{Na}_{2} \mathrm{CO}_{3} 1$ mmol, DMF $5 \mathrm{~mL}, \mathrm{O}_{2} 0.1 \mathrm{MPa}$, (a) $60^{\circ} \mathrm{C}, 90 \mathrm{~min}$ (b) $120^{\circ} \mathrm{C}$.
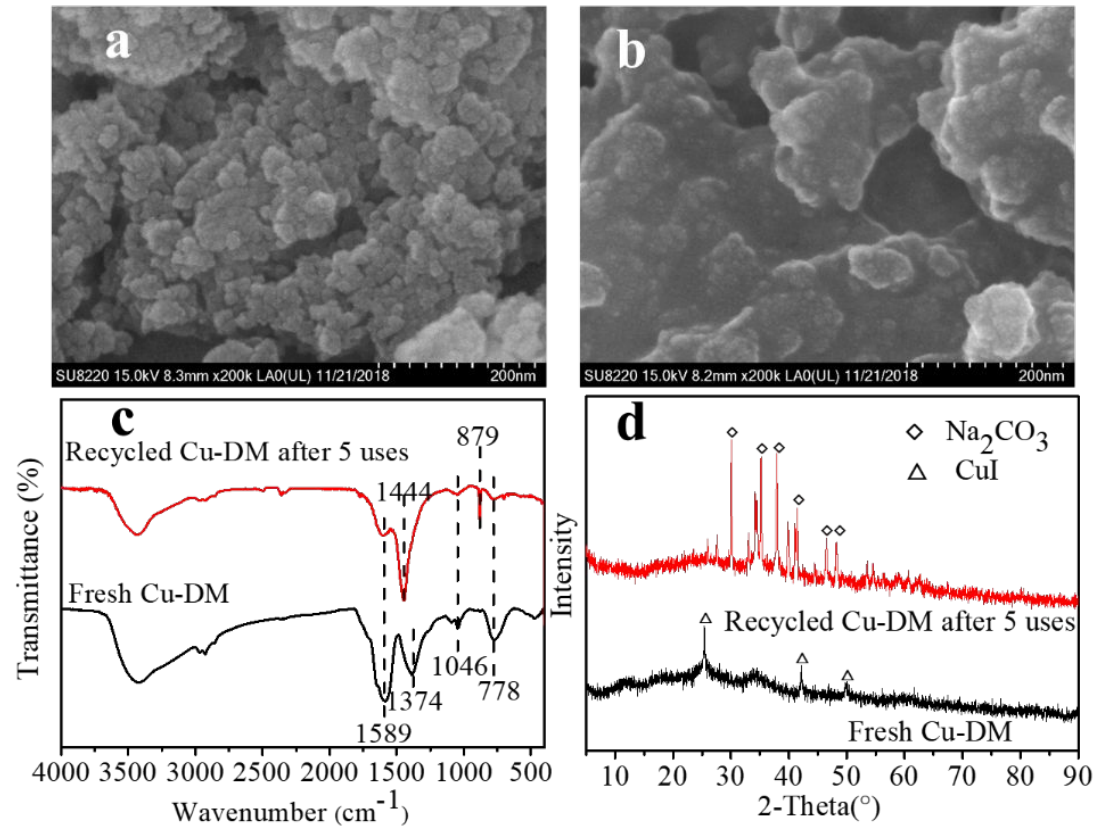

Figure $\mathbf{S 4}$ Comparison of the freshly prepared and recycled $\mathrm{Cu}-\mathrm{DM}$ catalysts after five reuses.

SEM of the fresh (a) and recycled catalyst (b), FTIR spectra (c), and XRD patterns (d).

The Cu-DM catalyst was characterized by SEM, XRD and FT-IR, and compared 
with the $\mathrm{Cu}-\mathrm{DM}$ catalyst. It can be seen that, compared with the newly prepared catalyst, the catalyst after recycling still exists in the form of particles (Figure S4a, b), with little change in the morphology and structure of the main body. As shown in Figure S4c, d, it can be seen from the FTIR spectrum that the main infrared characteristic peak of the catalyst still exists after cycling, and there is no significant change compared with the fresh catalyst. The characteristic peak of sodium carbonate in the XRD pattern is caused by the fact that the sodium carbonate added in the oxidation reaction is not separated out ${ }^{17}$. Meanwhile, the new peak $\left(1444 \mathrm{~cm}^{-1}, 879\right.$ $\mathrm{cm}^{-1}$ ) in FTIR is also caused by sodium carbonate residue ${ }^{9,18}$. The analysis of catalyst structure showed that $\mathrm{Cu}-\mathrm{DM}$ had no obvious structural changes before and after cyclic use, and the catalyst had good structural stability.

\section{S1.5 Analysis of catalytic mechanism}

According to literature reports, the oxidation mechanism of alcohols catalyzed by copper catalysts varies greatly with the composition of the catalyst system and the reaction conditions. Under the condition of the participation of TEMPO, the reaction mechanism mainly includes two kinds. One kind thinks that $\mathrm{TEMPO}^{+}$is a real oxidant. TEMPO is first oxidized to $\mathrm{TEMPO}^{+}$, and then oxidized to alcohols by $\mathrm{TEMPO}^{+}$, making the system acidic ${ }^{19-21}$. The other is the direct oxidation of alcohols by the TEMPO radical, with the help of copper ions, which requires the presence of a base ${ }^{20-22}$. According to the experimental results of $\mathrm{Cu}-\mathrm{DM}$ catalyst, the system in this paper requires the presence of alkali to play a good catalytic effect. Therefore, the mechanism of $\mathrm{Cu}-\mathrm{DM}$ catalytic oxidation of alcohols is more in line with the second 
one. The specific mechanism is as follows: the substrate benzyl alcohol first forms an intermediate with the copper active center of Cu-DM catalyst, and TEMPO is then combined with the copper active center of the intermediate. In this process, benzyl alcohol is oxidized into benzaldehyde by $\mathrm{Cu}-\mathrm{DM}$ and TEMPO. Meanwhile, divalent copper and TEMPO in $\mathrm{Cu}-\mathrm{DM}$ catalyst were reduced to monovalent copper and TEMPOH, respectively. Subsequently, monovalent copper and TEMPOH were oxidized into divalent copper and TEMPO by oxygen, and continued to participate in the reaction until the substrate was completely consumed and converted into benzaldehyde $21,23,24$.

\section{References}

(1) Naeimeh B.L.,Samahe S.CuI@Sulfur-functionalized halloysite nanoclay: a novel recyclable catalyst for the ultrasonic-assisted synthesis of propargylamines: a combination of experimental and DFT simulation. Res Chem Intermediat 2018; 44: $6351-6368$.

(2) Nagaraj A., Amarajothi D. $\mathrm{Cu}_{3}(\mathrm{BTC})_{3}$ as a viable heterogeneous solid catalyst for Friedel-Crafts alkylation of indoles with nitroalkenes. J Colloid Interf Sci 2017; 494: 282-289.

(3) Li Y., Wang LJ, Fan HL, Ju SG, Wang H, Mi J. Removal of Sulfur Compounds by a Copper-Based Metal Organic Framework under Ambient Conditions. Energ Fuel 2014; 29: 298-304.

(4) Gong W, Chen C, Zhang Y, Zhou HJ, Wang HM, Zhang HM, Zhang YX, Wang GZ, Zhao HJ. Efficient Synthesis of Furfuryl Alcohol from 
H2-Hydrogenation/Transfer Hydrogenation of Furfural Using Sulfonate Group Modified Cu Catalyst. ACS Sustain Chem. Eng.2017; 5: 2172-2180.

(5) Liu JH, Zhang AF, Jiang X, Liu M, Sun YW, Song CS, Guo XW. Selective CO2 Hydrogenation to Hydrocarbons on Cupromoted Fe-based Catalysts: Dependence on Cu-Fe Interaction. ACS Sustain Chem. Eng. 2018; 6: 10182-10190.

(6) Ania C.O., Seredych M., Rodriguez-Castellon E., Bandosz TJ. New copper/GO based material as an efficient oxygen reduction catalyst in an alkaline medium: The role of unique $\mathrm{Cu} / \mathrm{rGO}$ architecture. Appl. Catal. B-Environ.2015; 163: 424-435.

(7) Diring S.p., Furukawa S., Takashima Y., Tsuruoka T, Kitagawa S. Controlled Multiscale Synthesis of Porous Coordination Polymer in Nano/Micro Regimes. Chem Mater 2010; 22: 4531-4538.

(8) Xue ZM, Zhang JL, Peng L, Han BX, Mu TC, Li JS, Yang GY. Poly(ethylene glycol) stabilized mesoporous metal-organic framework nanocrystals: efficient and durable catalysts for the oxidation of benzyl alcohol. Chemphyschem 2014; 15(1): $85-89$

(9) Sha YF, Li N, Zhi KD, Song YM, Liu QS, Zhou HC. Novel and Efficient Cu-based Catalyst Constructed by Lignite Alkali-Oxygen Oxidation Products for Selective Aerobic Oxidation of Alcohols to Aldehydes. Fuel 2019; 257: 116042.

(10) Dhakshinamoorthy A., Alvaro M., Garcia H. Aerobic Oxidation of Benzylic Alcohols Catalyzed by Metal-Organic Frameworks Assisted by TEMPO. ACS Catal, 2010, $1(1): 48-53$

(11) Peng L., Zhang J., Xue Z., Han B.X., Sang X.X., Liu C.C., Yang G.Y. 
Highly mesoporous metal-organic framework assembled in a switchable solvent. Nat Commun 2014, 5(1):

(12) Zhang X., Dong W., Luan Y., Yang M., Tan L., Guo Y.G., Gao H.Y., Tang Y.H., Dang R., Li J., et al. Highly efficient sulfonated-polystyreneCu(II)@Cu3(BTC)2 core-shell microsphere catalysts for base-free aerobic oxidation of alcohols. J Mater Chem A 2015, 3(8): 4266-4273

(13) Liu Z., Shen Z., Zhang N., Zhong W., Liu X.M. Aerobic Oxidation of Alcohols Catalysed by $\mathrm{Cu}(\mathrm{I}) / \mathrm{NMI} / \mathrm{TEMPO}$ System and Its Mechanistic Insights. Catal Lett 2018, 148(9): 2709-2718

(14) Hoover J.M., Stahl S.S. Highly practical copper(I)/TEMPO catalyst system for chemoselective aerobic oxidation of primary alcohols. J Am Chem Soc 2011, 133(42): 16901-16910

(15) Zhao Y., Yu C., Wu S., Zhang W.L., Xue W.L., Zeng Z.X. Synthesis of Benzaldehyde and Benzoic Acid by Selective Oxidation of Benzyl Alcohol with Iron(III) Tosylate and Hydrogen Peroxide: A Solvent-Controlled Reaction. Catal Lett 2018, 148(10): 3082-3092

(16) Bai C., Li A., Yao X., Liu H.L., Li Y.W. Efficient and selective aerobic oxidation of alcohols catalysed by MOF-derived Co catalysts Green Chem 2016, 18(4): 1061-1069

(17)Bernal SA, Provis JL, Myers RJ, Nicolas RS, Van Deventer JS. Role of carbonates in the chemical evolution of sodium carbonate-activated slag binders. Mater Struct 2014; 48: 517-529. 
(18)Frangini S.,Scaccia S. Influence of lanthanum carbonate additions on thermal stability of eutectic lithium-sodium carbonate near its melting point. Thermochim Acta 2013; 551: 33-39.

(19) Cecchetto, A., Fontana, F., Minisci, F., Recupero F. Efficient $\mathrm{Mn}-\mathrm{Cu}$ and Mn-Co-TEMPO-catalysed oxidation of alcohols into aldehydes and ketones by oxygen under mild conditions. Tetrahedron Lett 2001; 42: 6651-6653.

(20) Geißlmeir, D., Jary, W.G., Falk, H. The TEMPO/copper catalyzed oxidation of primary alcohols to aldehydes using oxygen as stoichiometric oxidant. Monatsh Chem 2005; 136: 1591-1599.

(21) Marais, L., Swarts, A. J. Biomimetic Cu/Nitroxyl catalyst systems for selective alcohol oxidation. Catalysts 2019; 9(5): 395-423.

(22) Gamez, P., Arends, I.W.C.E., Sheldon, R. A., Reedijk J. Room temperature aerobic copper-catalysed selective oxidation of primary alcohols to aldehydes. $A d v$ Synth Catal 2004; 346:805-811.

(23) Hill, N. J., Hoover, J.M., Stahl, S.S. Aerobic alcohol oxidation using a copper( I ) /TEMPO catalyst system: a green, catalytic oxidation reaction for the undergraduate organic chemistry laboratory. J Chem Educ 2013; 90(1): 102-105.

(24) Mei, Q Q, Liu, H.Z, Yang, YD, Liu HY, Li SP, Zhang P, Han BX. Base-free oxidation of alcohols over copper-based complex under ambient condition. ACS Sustain Chem Eng 2018; 6: 2362-2369. 